phong trong đánh giá sự hài lòng của nhân viên y tế với các dạng thuốc của sevoflurane tại Việt Nam.

\section{KẾT LUÂN}

Với sự hài lòng của bác sĩ và kỹ thuật viên gây mê đối với sevoflurane BDG cao hơn sevoflurane Gx ở hầu hết các tiêu chí liên quan đến an toàn người bệnh, an toàn cho nhân viên $y$ tế, tổng điểm hài lòng của sevoflurane BDG cao hơn Gx ở cả bác sĩ lẫn kỹ thuật viên gây mê. Với cả hai đối tượng bác sĩ và kỹ thuật viên gây mê, điểm hài lòng đối với tiêu chí "chi phí sử dụng thuốc gây mê" không có sự khác biệt có ý nghĩa thống kê giữa sevoflurane BDG và GX.

\section{TÀI LIÊU THAM KHẢO}

1. Livertox: Clinical and Research Information on Drug-Induced Liver Injury (2014) "Drug Record: Sevoflurane", U.S. National Library of Medicine

2. Nandalan S. P., Eltringham R. J. , Fan Q. W. (2005). Cost-effectiveness of basal flow sevoflurane anaesthesia using the Komesaroff vaporizer inside the circle system. Anaesth Intensive Care, 33(5): p. 609-15.

3. Byon H. J., et al. (2015). An open-label comparison of a new generic sevoflurane formulation with original sevoflurane in patients scheduled for elective surgery under general anesthesia. Clin Ther, 37(4): p. 887-901.

4. Yamakage M., et al. (2007). Analysis of the composition of 'original' and generic sevoflurane in routine use. Br J Anaesth, 99(6): p. 819-23.

5. Portella A. A., et al. (2010). A double-blind comparative study between Generic Sevoflurane and Sevorane $^{\mathrm{TM}}$. Rev Bras Anestesiol, 60(5): p. 466-74.

6. Yasny J. S. and White J. (2012). Environmental implications of anesthetic gases. Anesth Prog, 59(4): p. 154-8.

7. Baker M. T. (2007). Sevoflurane: Are there differences in products?. Anesthesia \& Analgesia, 104(6): p. 1447-1451.

8. Grigoroudis E. and Spyridaki O. (2003). Derived vs. stated importance in customer satisfaction surveys. Operational Research, 3: p. 229-247.

\title{
KẾT QUẢ ĐÎ̂̀U TRỊ PHẪU THUÂT BÊNNH NHÂN CHẤN THƯƠNG CộT SỐNG CỔ CAO BẰNG PHƯƠNG PHÁP NẸP CỔ CHẨM
}

Nguyễn Viết Lực ${ }^{1}$, Ngô Thanh Tú2, Võ Văn Thanh ${ }^{1,2}$, Nguyễn Lê Bảo Tiến ${ }^{2}$

\section{TÓM TẮT}

Muc tiêu: Đánh giá kết quả điêu tri phẫu thuât bệnh nhân chấn thương cột sống cổ cao bằng phương pháp nẹp cổ chẩm. Phương pháp: Thiết kế theo phương pháp mô tả, nghiên cứu hồi cứu kết hợp tiến cứu trên 31 bênh nhân. Kết quả: Tỷ lề bệnh nhân đau cơ giảm tử $100 \%$ còn $27,5 \%$ và tỷ lệ co cứng cơ giảm $61,3 \%$ còn 27,5 (với $p=0,005$ ). Trước mổ, tỷ lế rối loạn cảm giác là $37,9 \%$ và tại thời điểm khám lại giảm còn $24,1 \%(p<0,005)$. Điểm VAS giảm từ $5,4 \pm$ 1,4 trước mổ xuống còn $2,1 \pm 1,3$ điểm sau mô (với $\mathrm{p}<0,005)$. Chỉ số JOA cải thiện từ 13,2 $\pm 3,6$ trước mổ lên $15,6 \pm 1,9$ điểm sau mổ $(p<0,005)$. Tỷ lệ liền xương của phẫu thuật và mức độ hài lòng của bệnh nhân lần lượt là $96,6 \%$ và $81 \%$. Kết luận: Sau phẫu thuật bằng phương pháp nẹp cổ chẩm, các bệnh nhân đều có sự phục hồi tốt các triệu chứng cơ năng và rối loạn cảm giác. Tỷ lệ liền xương của phẫu thuật và mức độ hài lòng của bệnh nhân cao.

Tư khóa: Chấn thương cột sống cổ cao, nẹp cổ chẩm, phẫu thuật.

${ }^{1}$ Đai hoc Y Hà Nôi

2Viện Chân thương Chỉnh Hinh, Bệnh viện Hữu nghị Viềt Đức

Chịu trách nhiệm chính: Nguyễn Lê Bảo Tiến

Email: bstiencsvd@gmail.com

Ngày nhân bài: 16.11.2020

Ngày phản biên khoa hoc: 5.01 .2021

Ngày duyệt bài: 18.01.2021

\section{SUMMARY}

THE RESULTS OF OF SURGICAL

TREATMENT WITH UPPER CERVICAL SPINE TRAUMA PATIENTS BY

OCCIPITOCERVICAL FUSION METHOD

Objective: To evaluate the results of surgical treatment with upper cervical spine trauma patients by occipitocervical fusion method. Methods: This is a descriptive, retrospective and prospective study of 31 patients. Results: The percentage of patients who muscle pain decreased from $100 \%$ to $27.5 \%$ and the percentage of muscle spasms decreased from $61.3 \%$ to $27.5 \%$ (with $p=0.005$ ). Before surgery, the dysaesthesia rate was $37.9 \%$ and it reduced to $24.1 \%$ at the time of re-examination $(p<0.005)$. The VAS point reduced from $5.4 \pm 1.4$ at preoperative time to $2.01 \pm 1.3$ at postoperative time (with $p<0.005$ ). The JOA index improved from $13.2 \pm 3.6$ before surgery to $15.6 \pm 1.9$ after surgery $(p<0.005)$. The percentage of bone knitting and the patient satisfaction were $96.6 \%$ and $81 \%$, respectively. Conclusion: After surgery by occipitocervical fusion method, the parents have good recovery of functional symptoms and dysaesthesia. The percentage of bone knitting and the patient satisfaction were high.

Keywords: Upper cervical spine trauma, occipitocervical fusion, surgical.

I. ĐẶT VẤN ĐỀ

Chấn thương cột sống cổ là chấn thương 
thường gặp, chiếm khoảng $6 \%$ trong tất cả những trường hợp đa chấn thương, $40 \%$ trường hợp có tổn thương thần kinh, có thể để lại hậu quả nặng nề như tổn thương thần kinh không hổi phục, thâm chí tử vong [1]. Dựa theo đặc điểm giải phẫu và chức năng, cột sống cổ cao bao gồm C0 (lồi cầu chẩm), C1 (đốt đội) và C2 (đốt trục), và hê thống dây chằng giữa chúng. Chấn thương cột sống cổ cao là những chấn thương phức hợp $\mathrm{C} 0, \mathrm{C} 1, \mathrm{C} 2$ hay còn gọi là vùng bản lề cổ chẩm [2]. Cột sống cổ cao rất linh hoạt về mặt chức năng, được liên hệ với nhau bởi hệ thống dây chằng và diện khớp phức tạp do vậy các hình thái tổn thương cũng đa dạng và phức tạp [3].

Nẹp cổ chẩm làm một trong những phương pháp điều trị chấn thương cột sống cổ cao, tuy nhiên chỉ định rất hạn chế, chỉ áp dụng trong một số tổn thương gây mất vững bản lể cổ chẩm [4]. Gần $50 \%$ chức năng quay cổ và cúi ưỡn nằm ở vùng bản lề cổ chẩm [2], vì vậy phẫu thuật nẹp cổ chẩm làm hạn chế rất nhiều vận động vùng cổ gây ảnh hưởng đến chất lượng cuộc sống của bệnh nhân. Do vị trí đặc trưng của phẫu thuật nẹp cổ chẩm liên quan đến cả cấu trúc xương chẩm và cột sống nên phẫu thuật này có thể gặp các tai biến như: tổn thương thần kinh, tồn thương mạch, rò dịch não tủy, nhiễm trùng, đau thần kinh chẩm...[5].

Trước đây đã có một số nghiên cứu về chấn thương cột sống cổ cao của Hoàng Gia Du (2012) về kĩ thuật vít qua khớp, Vũ Văn Cường (2018) về kĩ thuật Harms... tuy nhiên chưa có nhiều công trình nghiên cứu về phương pháp nẹp cổ chẩm trong điều trị chấn thương cột sống cổ cao.

Vì vậy, chúng tôi tiến hành nghiên cứu đề tài này nhằm đánh giá kết quả điều trị phẫu thuật bệnh nhân chấn thương cột sống cổ cao bằng phương pháp nẹp cổ chẩm.

\section{II. ĐỐI TƯỢNG VÀ PHƯƠNG PHÁP NGHIÊN CỨU}

2.1. Đối tượng nghiên cứu. Gồm 31 bệnh nhân được chẩn đoán xác định chấn thương cột sống cổ cao và được phẫu thuật nẹp cổ chẩm.

* Tiêu chuẩn lựa chọn bệnh nhân trong nhóm nghiên cứu:

- Tất cả những bệnh nhân đã được chẩn đoán xác định là chấn thương cột sống cổ cao có chỉ định nẹp cổ chẩm.

- Hồ sơ bệnh án đầy đủ.

- Bệnh nhân đồng ý tham gia nghiên cứu.

* Tiêu chuấn loại trư:

- Những bệnh nhân chấn thương kèm theo các tổn thương nặng.

- Những bệnh nhân có các bệnh mạn tính, có các tổn thương ung thư hay lao.

Địa điểm nghiên cứu: Bệnh viện Hữu nghị Việt Đức.

Thời gian nghiên cứu: Từ 01 tháng 1 năm 2018 tới 01 tháng 7 năm 2020.

\subsection{Phương pháp nghiên cứu}

* Thiết kế theo phương pháp mô tả, nghiên cứu hồi cứu kết hợp tiến cứu.

* Xử lý số liệu. Số liệu sau khi thu thâa được làm sạch và nhập vào máy tính. Xử lý và phẩn tích sổ liệu bằng phần mềm thống kê y học SPSS 20.0. Mức ý nghĩa thống kê alpha $=0,05$ được áp dụng.

\section{KẾT QUẢ NGHIÊN CỨU}

3.1 Đánh giá sự cải thiện triệu chứng cơ năng và mức độ hồi phục rối loạn cảm giác.

Bảng 3.1. Sự cải thiện triệu chứng cơ năng và hồi phục rối loạn cảm giác sau khám lại

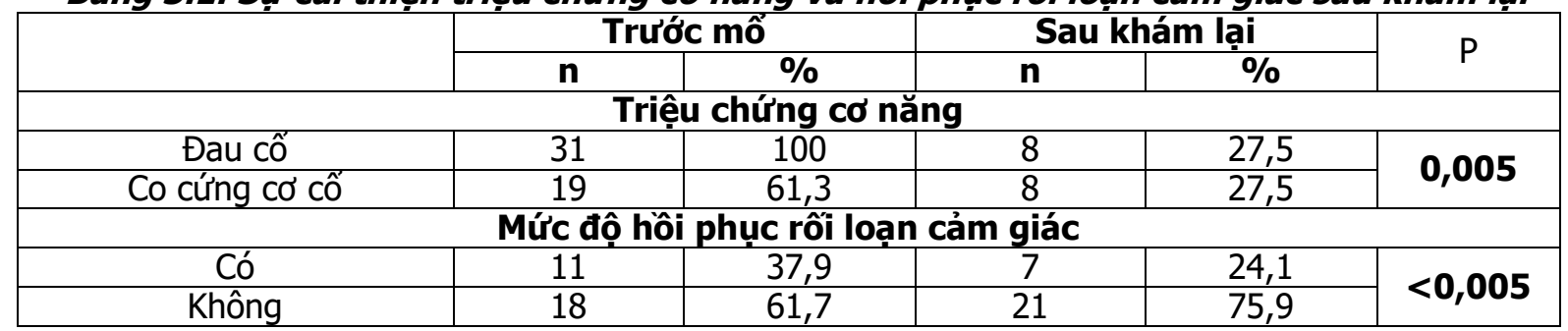

Tỷ lệ đau cổ trước mổ là $100 \%$, sau mổ còn $27,5 \%$. Tỷ lệ co cứng cơ cổ trước mổ là $61,3 \%$, sau mổ là $27,5 \%$. Sự khác biệt này có ý nghĩa thống kê với $p=0,005$.

Trước mổ, tỷ lệ rối loạn cảm giác là 37,9\%, tại thời điểm khám lại giảm còn $24,1 \%$, có ý nghĩa thống kê $p<0,005$.

3.2 Đánh giá mức độ đau và tổn thương tủy cổ trước mổ và sau mổ

Bảng 3.2. So sánh chỉ số VAS và JOA trước mổ và sau mổ

\begin{tabular}{|c|c|c|c|}
\hline & Trước mố & Sau mổ & P \\
\hline Điếm VAS $(X$ & $5,4 \pm 1,4$ & $2,1 \pm$ & 0,0001 \\
$\pm \mathrm{SD})$ (điểm) & 1,3 & 0,0 \\
\hline $\begin{array}{c}\text { Điê̂́m JOA }(X \\
\pm \text { SD) (điểm) }\end{array}$ & $13,2 \pm$ & $15,6 \pm$ & 0,0001 \\
\hline & 3,6 & 1,9 & \\
\hline
\end{tabular}


Tại thời điểm khám lại, mức độ đau trung bình của bệnh nhân nằm trong nhóm không đau hoặc tất ít đau giảm từ $5,4 \pm 1,4$ trước mố xuống còn $2,1 \pm 1,3$ khi khám lại. Có sự khác biệt về chỉ sô VAS trước mổ và sau khám lại, sự khác biệt này có ý nghĩa thống kê p<0,05 (Bảng 3.2).

Có sự tăng lên về chỉ số JOA sau mổ so với trước mổ, từ 13,2 $\pm 3,6$ lên $15,6 \pm 1,9$ điểm sau mổ. Sự tăng lên này có ý nghĩa thống kê $(p<0,005)$.

3.3 Đánh giá mức độ liền xương và độ hài lòng của bệnh nhân sau phẫu thuật

Bảng 3.3. Đánh giá mức độ liền xương và độ hài lòng của bệnh nhân

\begin{tabular}{|c|c|c|}
\hline & Tân số (n) & Tí lệ (\%) \\
\hline \multicolumn{3}{|c|}{ Mức độ liền xương } \\
\hline Liền xương & 28 & 96,6 \\
\hline Không liền xương & 1 & 3,4 \\
\hline \multicolumn{3}{|c|}{ Mức độ hài lòng } \\
\hline Có & 25 & 81 \\
\hline Không & 6 & 19 \\
\hline
\end{tabular}

Tỷ lệ liền xương là 96,6\%. Tỷ lệ không liền xương là $3,4 \%$, đây là bệnh nhân có nhiễm trùng sau mổ. Có $81 \%$ bệnh nhân hài lòng với cuộc sống hiện tại sau mổ. Tỷ lệ bệnh nhân khồng hài lòng là 19\% (Bảng 3.3).

\section{BÀN LUÂN}

4.1. Sự cải thiện triệu chứng cơ năng và mức độ hồi phục rối loạn cảm giác. Trước phẫu thuật, triệu chứng đau cổ xuất hiện ở 93,5\% bệnh nhẩn, sau mổ là 27,5\% bệnh nhân các triệu chứng khác đều giảm rõ rệt và sự khác biệt này có ý nghĩa thống kê. Các nghiên cứu của các tác giả trong nước cũng cho rằng sau mổ triệu chứng đau cổ đều giảm, theo Vũ Văn Cường (2018) tỉ lệ này giảm từ $100 \%$ xuống còn $21,2 \%$ [6]. Triệu chứng hạn chế vận động vùng cố trong nghiên cứu của chúng tôi cũng giảm rõ sau phẩu thuật, tuy nhiên do phẫu thuật nẹp cổ chẩm làm hạn chế vận động cổ nên sự giảm này ít hơn các nghiên cứu khác.

Sự phục hồi rối loạn cảm giác cũng là một trong những tiêu chí để đánh giá phục hồi tủy. Tỷ lệ bệnh nhân có rối loạn cảm giác trước mổ là $37,9 \%$ giảm còn $24,1 \%$ sau khám lại. Chúng tôi kêt luận rằng phẫu thuật làm giảm tỉ lệ rối loạn cảm giác có ý nghĩa thống kê.

4.2. Sự phục hồi theo thang điểm VAS và chỉ số JOA. Sau khi khám lại, tất cả các bệnh nhân của chúng tôi đều có sự cải thiện về mức độ đau cổ theo thang điểm VAS. Nghiên cứu của chúng tôi có chỉ số VAS trung bình trước mổ là $5,4 \pm 1,4$ điểm, sau mổ đã giảm xuống còn 2,1 $\pm 1,3$ điểm, có ý nghĩa thống kê với $p<0,05$, kết quả tương tự với nghiên cứu của Yong $\mathrm{Hu}$ cho thấy mức độ đau theo thang điểm VAS trước mổ là $5,4 \pm 2,2$ điểm, sau mổ là $1,3 \pm 0,9$ điểm [7].

Trong nghiên cứu của chúng tôi, chỉ số JOA trung bình trước mổ là 13,2 $\pm 3,6$ điểm, sau mổ chỉ số này là $15,6 \pm 1,9$ điểm. Có sự cải thiện về chỉ số JOA, sự cải thiện này có ý nghĩa thống kê $(p<0,05)$, tương tự với nghiên cứu của Yong Hu [7].

4.3. Đánh giá mức độ liền xương và mức độ hài lòng của bệnh nhân. Trong phẫu thuật cột sống cố cao lối sau, mục đính chính của tất cả các phương pháp phẫu thuật đó là đạt được liền xương lối sau. Trong nghiển cứu của chúng tôi, tỉ lệ liền xương đạt 96,6\%. Tỷ lệ liền xương trong phẫu thuật Harms của Vũ Vắn Cường là 95,45\% [6] và Tỷ lệ liền xương sau mổ nẹp cổ chẩm theo Yong Hu là 98,5\% [7]. Cho thấy phẫu thuật nẹp cổ chẩm cho tỉ lệ liền xương cao.

Trong nghiên cứu của chúng tôi tất cả các bệnh nhân đều bi mất khả năng quay cổ sang hai bên, hạn chế cúi ưỡn, trong đó có $81 \%$ bệnh nhân hài lòng với sự hạn chế này, cao hơn kết quả nghiên cứu của Yong $\mathrm{Hu}$ với $70 \%$ là tỷ lệ bệnh nhân hài lòng vì hạn chế vận động cổ [7]. Bệnh nhân của chúng tồi trước phẫu thuật đều được giải thích rõ về những hạn chế này, và phẩu thuật nẹp cổ chẩm vẫn được coi như phương án cuối cùng khi phẫu thuật cho bệnh nhân chấn thương cột sống cổ cao.

\section{KẾT LUÂN}

Sau phẫu thuật bằng phương pháp nep cổ chẩm, các bệnh nhân đều có sự phục hồi tốt các triệu chứng cơ năng và rối loạn cảm giác. Tỷ lệ liền xương của phẫu thuật và mức độ hài lòng của bệnh nhân cao.

\section{TÀI LIỆ THAM KHẢO}

1. Negrelli, M.A.C., et al., Traumatic injuries of the cervical spine: current epidemiological panorama. Acta ortopedica brasileira, 2018. 26(2): p. 123-126.

2. Herkowitz, H.N., et al., Rothman-Simeone The Spine E-Book: Expert Consult. Vol. 1. 2011: Elsevier Health Sciences.

3. Benzel, E.C. and P.J. Connolly, The cervical spine. 2012: Lippincott Williams \& Wilkins.

4. Platzer, $\mathbf{P}_{\text {., }}$ et al., Delayed or missed diagnosis of cervical spine injuries. Journal of Trauma and Acute Care Surgery, 2006. 61(1): p. 150-155.

5. Winegar, C.D., et al., A systematic review of occipital cervical fusion: techniques and outcomes: a review. Journal of Neurosurgery: Spine, 2010. 13 (1): p. 5-16.

6. Vũ Văn Cường, Nghiên Cứu Ứng Dụng Kỹ Thuật Harms Cải Tiến Trong Điều Trị Chấn Thương Mất Vững C1 - C2. Luận Án Tiến Sĩ y Học, Đại Học Y Hà Nội, 2018.

7. Hu, Y., et al., Comparison of occipitocervical and atlantoaxial fusion in treatment of unstable Jefferson fractures. Indian Journal of Orthopaedics, 2017. 51: p. 28-35. 